\title{
Early Diagnostics of Congenitated Conscious False Hernia Own Diaphragm
}

\author{
Rayanov NV* and Rayanova RN \\ Russia
}

ISSN: 2576-9200

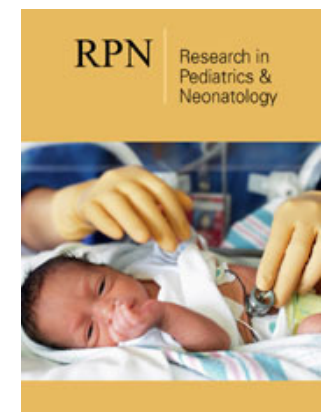

${ }^{* 1}$ Corresponding author: Rayanov NV, Russia

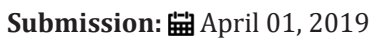

Published: 㠿April 17, 2019

Volume 3 - Issue 3

How to cite this article: Rayanov $\mathrm{N}$, Rayanova R . Early Diagnostics of Congenitated Conscious False Hernia Own Diaphragm. Res Pediatr Neonatol. 10(2). RPN.000563.2019.

DOI: 10.31031/RPN.2019.03.000563

Copyright@ Rayanov NV, This article is distributed under the terms of the Creative Commons Attribution 4.0 International License, which permits unrestricted use and redistribution provided that the original author and source are credited.

\begin{abstract}
Congenital diaphragmatic hernia (EDC) is a malformation of the thoracic-abdominal barrier, in which the abdominal organs are transported into the chest through the natural pathological openings in the diaphragm. The frequency of occurrence in newborns is 1: 2500-1: 5000, which is $8 \%$ of all congenital anomalies. Diaphragmatic hernia is divided into three main groups: hernia proper diaphragm (false, true), hiatal hernia (true), hernia of the anterior part of the diaphragm. The article presents a clinical case of early diagnosis of congenital false hernia of the diaphragm itself.
\end{abstract}

Keywords: Congenital diaphragmatic hernia; Newborns; Diagnosis

\section{Case Report}

False hernias of the diaphragm proper are the most severe; left-sided hernias are more common. The clinic depends on the size of the defect, their localization, the number and size of the displaced organs. In this case, the functions of respiration, digestion and cardiovascular activity are most often violated. A diaphragmatic hernia may not be detected for a long time, or it manifests itself immediately after birth in the maternity ward with "asphyxial restraint", a progressive deterioration in the general condition of the newborn, accompanied by an increase in cyanosis.

Prenatal diagnosis of congenital diaphragmatic hernia includes an ultrasound scan, if necessary, MRI. Congenital false diaphragmatic hernia of the actual diaphragm in a newborn ("asphyxial infringement") is an absolute indication for immediate surgery. In our practice, we observed a false hernia of the diaphragm of a newborn in the maternity ward. Newborn, born with a body weight of 2600gr, an Apgar score of 4-5 points. (data on the course of pregnancy is not available, because a woman from a rural area was not registered with an obstetriciangynecologist for pregnancy, there are no ultrasound data from the examination: at 12-14 weeks, 20-22 weeks and 30-32 weeks of pregnancy). At birth, immediately paid attention to the weakness, lethargy of the newborn and cyanosis of the skin. On examination, difficult, shallow, rapid breathing involving auxiliary muscles. BH-42 in 1min. During auscultation of the left breathing is sharply weakened, peristaltic intestinal noise is heard. Heart tones are shifted to the right, HR-156 in $1 \mathrm{~min}$ [1-7].

An emergency survey of the chest and abdominal organs was performed, where a sharp displacement of the mediastinum organs to the right and cellular cavities filled with intestinal loop gas were detected. Considering the clinical data, severe lethargy, increasing cyanosis, rapid shallow breathing, when viewed from the participation of auxiliary muscles in the act of breathing. Auscultatory weakening of breathing on the left, heart tones shifted to the right. On radiography, the sharp displacement of the mediastinal organs to the right and the intestinal noise is heard in the chest cavity on the left. Clinical diagnosis is made congenital diaphragmatic restrained hernia on the left (Figure 1).

For further treatment through the RCC, the newborn was transferred to the RCCH (Ufa) (after the probe was installed in the stomach through the nose) for surgical treatment, where she was successfully operated on with thoracoscopic access, reducing intestinal loops and closing the diaphragm defect. Complications in the postoperative period was not observed. The patient was discharged 15 days after surgery in a satisfactory condition. The chest X-ray of the organs of the chest and abdominal cavity was performed. The child was examined after 1.3 months and at the age of one. Mother has no complaints. The general condition 
is satisfactory. Body mass is $9.5 \mathrm{~kg}$, artificial feeding. The skin is clean, there is no cyanosis. Over the lungs during auscultation, puerile breathing, no wheezing. Heart tones are clear, rhythmic.
The abdomen is not swollen, oval, soft on palpation, pathological formations are not determined. According to the mother, the chair is decorated, it urinates on its own.

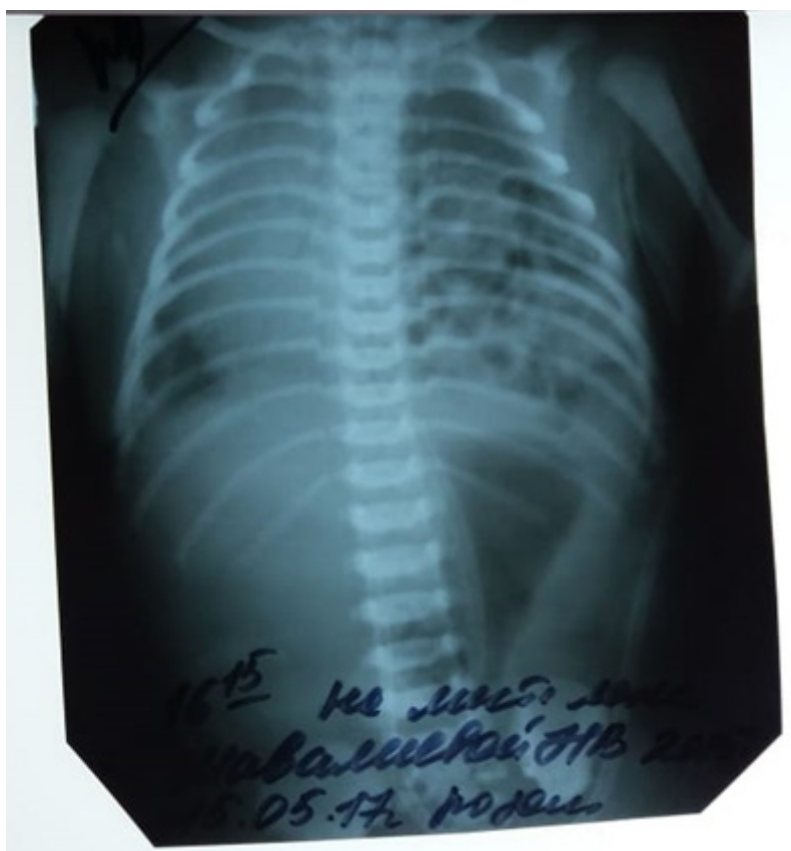

Figure 1.

\section{Findings}

A. Timely diagnosis of congenital diaphragmatic hernia with incarceration in the maternity ward and transfer of the newborn to the RCCH allowed to exclude terrible complications.

The decisive importance for the diagnosis of congenital diaphragmatic hernia is a survey X-ray of the chest and abdominal organs, where the displacement of the mediastinal organs to the right and the detection of intestinal loops in the chest is detected.

\section{References}

1. Avrelkina EV (2014) Algorithm for the study of the lungs and the diaphragm with a false left-sided congenital diaphragmatic hernia. Current Problem of Science and Education 6: 76-78.
2. Bairov GA (1983) Emergency surgery of children. A guide for doctors.

3. Balychevtseva, Gadetskaya SG, Vakulenko SI, Bezuglova IA, Denisenko T (2012) Diaphragmatic hernia: diagnostic features. Health 3: 30-32.

4. Gumerov AA (1986) Surgical treatment of congenital diaphragmatic hernia. Avto ref dis Med Science, p. 465.

5. Petrova LV (2015) Surgical correction of false diaphragmatic hernia in newborns. Russian Bulletin of Pediatric Surgery, Anesthesiology and Resuscitation 5(3): 75-77.

6. Slepkov AK, Gordienko Y, Ponomarenko A, Tarapurova EN, Soroka VP, et al. (2012) Diagnosis of congenital diaphragmatic hernia in fetuses and newborns. Child Health 2: 34-36.

7. Smirnova SV, Razumovsky Yu, Makrushina G (2012) Modern methods of correction of congenital diaphragmatic hernia in newborns. Questions of Practical Pediatrics 7(2): 3-34. 